Fecha de recepción: marzo 2021

Fecha de aprobación: abril 2021

Fecha publicación: mayo 2021

\section{Ni roja ni azul, verde infinito. Convergencia mediática y arqueología de los medios en el Universo Matrix}

\author{
Pamela Gionco ${ }^{(1)}$
}

\begin{abstract}
Resumen: El Universo Matrix se construye a partir de obras que van del cine al videojuego, la historieta y la animación. Jenkins (2008) reconoce en este mundo diegético, características que definen la convergencia mediática, como la cocreación y la compresión aditiva. La sinergia de la producción audiovisual hace permeables las formas del cine, la animación digital y el videojuego. Por otra parte, la representación de y por las tecnologías digitales permiten trazar relaciones tanto con el pre-cine como con la cultura digital, desde la perspectiva de la arqueología de los medios (Parikka, 2012).

En este trabajo se analiza la construcción de esta narrativa transmedia que Jenkins identifica y caracteriza, al tiempo que se reconoce una convergencia en las técnicas de realización y consumo de obras digitales.
\end{abstract}

Palabras clave: cine digital - videojuegos - convergencia - arqueología de los medios transmedia - Matrix.

[Resúmenes en inglés y portugués en las páginas 48-49]

(1) Licenciada y Profesora en Artes (UBA). Diplomada en Preservación y Restauración Audiovisual (UBA). Docente regular del Departamento de Artes (FFyL, UBA). Investigadora del CIyNE - Centro de Investigación y Nuevos Estudios sobre Cine (Instituto de Historia del Arte Argentino y Latinoamericano "Luis Ordaz", FFyL, UBA).

Es miembro de la Asociación Argentina de Humanidades Digitales (AAHD), la Asociación Argentina de Estudios de Cine y Audiovisual (AsAECA) y la Red Argentina de Preservadorxs Audiovisuales (RAPA). Sus intereses de investigación se vinculan con el estudio de las técnicas de representación, el patrimonio material, la historia del cine, la animación y la digitalización en unidades de información (museos, bibliotecas y archivos). Integra el comité de organización del Frikiloquio - Coloquio de Humanidades y Ciencias Sociales sobre culturas y consumos freaks. 


\section{Introducción}

La primera imagen del Universo Matrix que aparece en pantalla, luego de los créditos iniciales de las compañías productoras (Warner Bros. y Village Roadshow) y el título (todo en un color verde artificial), es un cuadrado verde titilando en la superficie de la pantalla negra, ubicado arriba a la izquierda. El sonido que le acompaña: una llamada telefónica que, se entenderá luego, sirve para establecer conexiones y un pequeño diálogo entre voces sin cuerpo (aún). Las tecnologías que evoca esta microsecuencia (la transmisión de datos dial-up, el monitor monocromo, incluso el llamado telefónico) ya (casi) no tienen referente en el mundo actual, son remanentes del constante devenir tecnológico.

A más de veinte años de la película Matrix (1999), esta obra audiovisual debe considerarse parte de la historia misma de la cultura digital, de la transformación de los medios de comunicación analógicos a los digitales, de la (auto)representación de las tecnologías de la información. Asimismo, la construcción narrativa multimedia que desarrollaron sus creadoras, las hermanas Wachowski, entre fines del siglo XX y principios del XXI ha sentado las bases para entender y definir el paradigma de las narrativas transmedia (Jenkins, 2008; Scolari, 2013).

A partir de un enfoque transdisciplinar entre los estudios de cine y medios, las teoría e historia de las artes y la historia social de la tecnología, se abordará la configuración de lo que se denomina Universo Matrix, compuesto hasta el momento por una trilogía de films (1999-2003), una colección de nueve cortometrajes de animación (2003), dos videojuegos para PC y consola (2003-2005), un videojuego multijugador en línea (2005-2009), cómics y webcómics (1999-2004), un sitio de Internet con contenidos exclusivos (1999-2009), además de otros productos de consumo y la cultura participativa del fandom que genera a su vez nuevos contenidos hasta la actualidad. Se encuentra además en producción la cuarta entrega cinematográfica, a cargo de Lana Wachowski ${ }^{1}$.

Cada una de las partes del Universo Matrix pueden entenderse como manifestaciones propias de la cultura visual digital (Darley, 2002), es decir, como experiencias culturales comunes, fenómenos emergentes de la cultura de masas, imágenes generadas por medios informáticos. En función de la producción, circulación y consumo de estas obras, la pregunta de este trabajo sobre las relaciones históricas y materiales que se establecen entre las técnicas involucradas en esos procesos con prácticas mediáticas previas o contemporáneas, alude a considerar las técnicas de realización de las obras audiovisuales, tanto de las películas como de los videojuegos, en el marco de la convergencia mediática. Con el objetivo de dar cuenta de las continuidades entre prácticas mediáticas, se propone identificar las tecnologías de la representación que operan en la construcción de este Universo desde la arqueología de los medios (Parikka y Huhtamo, 2011; Parikka, 2012; Alsina, Rodríguez Granell y Hofman, 2018). Este enfoque teórico, heredero en parte de las teorías de Marshall McLuhan y de la "arqueología del saber" foucaultiana, entre otras líneas de investigación, se manifiesta recientemente como un giro material en el estudio de los medios, ante el surgimiento de las "nuevas" tecnologías digitales. Apunta a entender, por ejemplo, los modos en lo que se conciben, circulan y se consumen las imágenes audiovisuales desde la cultura material, a partir del uso de aparatos, procesos y soportes físicos de la información, al tiempo que permite establecer relaciones que enriquecen la historia de la representación 
visual mediada tecnológicamente y redimensionar así los objetos culturales contemporáneos en relación al pasado. Tal como afirma Jussi Parikka (2012), la arqueología de los medios considera las culturas mediáticas como capas, pliegues de tiempo y materialidad "donde el pasado podría descubrirse repentinamente de nuevo y las nuevas tecnologías se vuelven obsoletas cada vez más rápido" (p. 13)².

El artículo está organizado en tres apartados. En la primera sección, se recopila la construcción narrativa transmediática del Universo Matrix (Jenkins, 2008), hilando los sucesos de una historia que se cuenta mediante distintos relatos (audio)visuales. En particular, se realiza un recorrido de los contenidos narrativos de las películas, entramados con algunos cortometrajes de animación y con los videojuegos. Luego, se enmarca el Universo Matrix en el contexto de las convergencias mediáticas (Jenkins, 2008; Scolari, 2013), tanto tecnológicas como representacionales, que habilitan el proceso de la remediación (Bolder y Grusin, 2011) entre el cine y los videojuegos mediante el cual se hibridan sus formas. Por último, se analiza las técnicas específicas aplicadas a la producción audiovisual de Universo Matrix, en relación con la historia del arte y de los medios, a partir de su dimensión material. Desde la arqueología de los medios, el estudio de las técnicas y los aparatos lleva a reconocer la apropiación digital de prácticas mediáticas del pasado.

La metodología utilizada en este trabajo se basa en el estudio cualitativo de las obras que componen el Universo Matrix, así como el análisis de fuentes documentales contemporáneas al estreno de las películas, los cortos y los videojuegos (críticas, reseñas, entrevistas) y textos posteriores que realizan relecturas de estas obras. Particularmente, se remite a fuentes que den cuenta de las cuestiones técnicas vinculadas a la producción audiovisual, la generación de imágenes y el consumo crítico, que contrastan con otras prácticas registradas de la historia de los medios, el cine y el arte.

\section{Narración transmediática}

El Universo Matrix se establece en la primera película de la saga, a partir de la cual se presenta a los personajes principales de la trama (Neo, Trinity y Morfeo), los oponentes (agentes, máquinas) y se describe el mundo narrativo en el cual se van a desarrollar los eventos. La diégesis se ubica en un futuro distópico con estilo cyberpunk en el cual máquinas con inteligencia artificial y la humanidad han mantenido un enfrentamiento durante siglos que destruyó el entorno natural. La mayoría de la humanidad se encuentra esclavizada por estos seres artificiales que se sirven de seres humanos como pilas de las cuales extraen electricidad, mientras proyectan en la mente de cada individuo un entorno virtual que recrea un simulacro de realidad ambientada en 1999, año del estreno del film. Esta configuración del Universo Matrix fue tan abundante en referencias como consistente visualmente, lo que le permitió instituirse como una película de culto (Jenkins, 2008):

Ante todo, la película cuenta con atractivos populares. Toda clase de elementos: ataques suicidas por fuerzas especiales de élite, impresionantes helicópteros, artes marciales a raudales, una historia casta pero apasionada de amor predes- 
tinado, monstruos de ojos saltones de primera categoría, ropa fetichista, cautiverio y tortura y osado rescate, y submarinos realmente extraordinarios (...) Hay exégesis cristiana, un mito del Redentor, una muerte y un renacimiento, un héroe en proceso de autodescubrimiento, La Odisea, Jean Baudrillard (mucho Baudrillard, lo mejor de la película), ingredientes ontológicos de ciencia ficción de la escuela de Philip K. Dick, Nabucodonosor, Buda, taoísmo, misticismo de las artes marciales, profecía oracular, telequinesis que dobla cucharas, magia de Houdini, Joseph Campbell y metafísica matemática gödeliana (B. Sterling, citado por H. Jenkins, 2008, p. 104).

Una de las claves narrativas que articulan la historia de Neo, el protagonista, es el momento en el que debe decidir si quiere ver la realidad tal cual es o mantenerse en la Matrix virtual. Como rito de pasaje, Morpheus le ofrece tomar una píldora roja para liberarse del yugo de las máquinas o una píldora azul para seguir en el mismo estado de simulación. A lo largo de la película, el rango cromático de la representación visual permite distinguir cada espacio. El color del mundo artificial creado por las máquinas (la Matrix) es verde, mientras que el futuro "real" es azul. Los tonos cálidos de la iluminación, por su parte, fueron utilizados para los espacios interiores como la habitación de Neo.

Durante el mismo año 1999, se publican en la Web una serie de cómics de diversas historias ambientadas en el Universo Matrix. Se trata de representaciones digitales de la cultura gráfica que acompañan el estreno de la película y se conciben como contenidos del sitio oficial de la película www.whatisthematrix.com (hoy ya no disponible) $)^{3}$. Los webcómics siguieron apareciendo organizados en series hasta 2004.

Luego del primer film, dado por el impacto comercial y cultural de la obra, las hermanas Wachowski tuvieron la posibilidad de elaborar durante cuatro años las ampliaciones narrativas y diegéticas de este universo que plasmaron en guiones tanto para largometrajes de cine como para otras modalidades visuales y audiovisuales: historietas, animación y juegos de computadora.

En la primera mitad del año 2003 se estrenó Animatrix, compilación de cortometrajes de animación de estilo japonés (animé) dirigidos por distintos directores. Si bien la primera pieza de la antología, Final Flight of Osiris (El último vuelo de Osiris, 2003), se presentó junto el film Dreamcatcher (Cazador de sueños, 2003), en muchos países los títulos no llegaron a proyectarse en salas de cine, sino que se editaron directamente para consumo doméstico (en VHS y en DVD). Todos los cortos de Animatrix se encuentran ambientados en el Universo configurado en la primera película. Algunas de las obras se sitúan en un tiempo anterior a la historia de Neo/Thomas Anderson, ampliando así la información narrativa que Morpheus le trasmite al protagonista luego de su "despertar". Es el caso, por ejemplo, de The Second Renaissance (El segundo Renacimiento, 2003), que se presenta en dos partes y toma contenidos narrativos del cómic Bits and pieces of information (1999) en el cual se desarrollan sucesos que desencadenan los conflictos no resueltos entre seres humanos y seres artificiales ${ }^{4}$.

Ahora bien, Final Flight of Osiris está directamente conectado con la trama narrativa principal de la primera película. Comienza con una secuencia inicial que incluye una sensual pelea entre un hombre y una mujer en el entorno virtual que había sido presentado como 
un "programa de entrenamiento", el dojo simulado en el cual Neo practica kung-fu con Morpheus. Luego de una alarma, los personajes salen de la simulación para descubrir que son perseguidos por centinelas, máquinas vigilantes y destructoras. En el intento de escape, el capitán de la nave Osiris reconoce lo que está sucediendo: las máquinas se dirigen a Zion, la última ciudad de seres humanos. La tripulación decide entonces, en un arriesgado acto suicida, enviar a través de la Matrix el mensaje de alerta al resto de las naves ante la inminente destrucción del último reducto de sobrevivientes.

El mismo año de estreno de Animatrix sale a la venta Enter the Matrix, el primer videojuego del Universo ${ }^{5}$, y se estrena Matrix Reloaded, la segunda película. El entramado narrativo entre ambas obras se construye en paralelo. En Enter the Matrix, juego de acción y combate en tercera persona, es posible elegir como avatar entre Niobe, reconocida como la mejor piloto, y Ghost, especialista con armas de fuego. Ambos protagonistas aparecen también como personajes secundarios de la trama que se desarrolla en la segunda película. La primera misión que se debe realizar en el videojuego es recuperar aquel mensaje dejado en la Matrix en el cortometraje Final Flight of Osiris, mientras que Matrix Reloaded comienza con esa información narrativa, pocos meses de los sucesos de la primera película. Las siguientes etapas del juego, como rescatar a Morpheus y a Trinity en la autopista, o volar una central eléctrica, complementan los contenidos narrativos de la película.

Hacia fin del 2003, se estrena la última película (hasta el momento) de la franquicia, $\mathrm{Ma-}$ trix Revolutions, que se propone cerrar la compleja historia de Neo, quien debe medirse con un oponente (Agente Smith) más poderoso que en las entregas anteriores. El relato retoma la historia de la anterior película y le da clausura narrativa a la (entonces) trilogía. Luego del estreno de este film, se mantiene activo el sitio web y aparecen nuevos webcómics. En la primera mitad del 2005, luego de pruebas realizadas durante el 2004, se pone en línea el MMORPG ${ }^{6}$ The Matrix Online. Ubicado temporalmente luego de la historia de Matrix Revolutions, los sucesos que ocurren en este entorno virtual se consideran eventos de la trama oficial del Universo Matrix, fomentando así la participación de usuarios y usuarias. La creación de personajes en este MMORPG se basa en la misma decisión que tuvo que tomar Neo en la primera película: tomar una píldora roja o una azul, para luego configurar las características del avatar. Los contenidos narrativos se organizan en capítulos, vinculadas a misiones a realizar por quienes juegan en línea, que se desbloquearon semana a semana, además de eventos en vivo y reuniones periódicas. Sony Online Entertainment, a cargo del juego, decide finalmente cerrar el sitio en 2009. Se publica un libro electrónico conmemorativo ${ }^{7}$ que recopila tanto las líneas narrativas del juego como las experiencias y memorias de jugadores y jugadoras.

A fines del 2005, sale al mercado para PC, PlayStation 2 y Xbox, The Matrix: The Path of $\mathrm{Neo}$. Esta última obra responde a un reclamo reiterado de quienes consumían activamente la franquicia que planteaba que no se había diseñado aún un juego en el cual se pudiera encarnar a Neo, el protagonista. La estrategia narrativa en este caso fue repasar la historia contada a partir de las tres películas, con variaciones, desde la perspectiva de este personaje. Ahora bien, hacia el final del juego, se introduce una secuencia audiovisual ambientada en el entorno virtual de entrenamiento (un espacio en blanco con solo dos sillones), en la cual se presentan los entonces hermanos Wachowski ${ }^{8}$, mediante personajes diseñados en 8 bits, que contrastan con el diseño 3D del espacio. En primera persona, las mentes creado- 
ras de este Universo plantean el problema que enfrentaron al condensar la trama de las tres películas en un videojuego. Mientras que el final de Matrix Revolutions, el protagonista su vida sacrifica para salvar tanto a la humanidad como a las máquinas, se plantea que esto resulta aburrido para un videojuego de acción y combate, por lo que deciden cambiar el final. El último jefe al que hay que vencer como Neo para terminar el juego, el oponente que presenta la mayor complejidad y desafío, es un mecha ${ }^{9}$ gigante comandado por múltiples Agentes Smith. Así, la compleja narrativa con reminiscencias bíblicas de las películas se modifica para potenciar la jugabilidad e interactividad del videojuego. Cada medio asume la narración audiovisual de un modo distinto, de acuerdo a su propia historia mediática, sin alterar el sentido del final: Neo vence al Agente Smith y salva el mundo.



Figura 1. Estructura narrativa de las principales obras audiovisuales del Universo Matrix, en relación a la trama principal (Elaboración propia de la autora).

\section{Convergencias mediáticas}

Las convergencias mediáticas son procesos por los cuales los medios mutan con una tendencia a la concentración que borra sus diferencias. Procesos complejos, que no suponen una única operación sino que es necesario reconocer diversos modos. Jenkins (2001) propone inicialmente al menos cinco modos de convergencia: tecnológica, económica, social, cultural y global. Por su parte, Carlos Scolari (2009) remite a Ramón Salavarría (2003) para reconocer que "la convergencia implica al menos cuatro dimensiones" (p. 95): convergencia empresarial, tecnológica, profesional y comunicativa. Las convergencias tecnológica y económica-empresarial son comunes a ambas propuestas. Es posible encontrar un antecedente a estas ideas en Roger Fidler (1998), quien denomina mediamorfosis a los procesos que se dan en todos los sistemas de medios. La convergencia es uno de los principios de estas transformaciones de los medios de comunicación (junto con la coevolución y la complejidad).

Con respecto a la convergencia económica-empresarial, tal como afirma Jenkins (2008), las narraciones transmediáticas implican grandes intereses económicos, concentrados en corporaciones multimedios (como Time-Warner, la corporación que produce Matrix), donde cada medio tiene su propio segmento de mercado ${ }^{10} \mathrm{y}$ cada obra se constituye como un nuevo punto de acceso al Universo Matrix. Proffitt, Tchoi y McAllister (2007) realizan 
un detallado análisis sobre este tema, en el cual reconocen a Matrix como un "flujo intertextual mercantilizado", una narrativa de múltiples mercancías, que integra estrategias de marketing orientadas a consumos específicos, además de desarrollo de tecnologías y gestión de licenciamientos.

La convergencia tecnológica también garantiza una sinergia en la producción mediática. En el caso de Matrix, al mismo tiempo que se filmaban las dos películas estrenadas en 2003, se generaban las imágenes cinemáticas del videojuego Enter the Matrix con el mismo equipo técnico y artístico. Desde el diseño de la producción audiovisual, esto se traduce en una optimización de los recursos y, en consecuencia, una reducción de los costos operativos del proceso que permite multiplicar los productos.

A partir del estudio del caso Matrix, Jenkins (2008) también reconoce otras dos características de la obra transmedia:

- Autoría cooperativa: Las hermanas Wachowski se implicaron personalmente en la configuración visual de la representación del Universo Matrix, convocando a técnicos y artistas de reconocida trayectoria, como el coreógrafo de artes marciales Woo-ping Yuen o la diseñadora de vestuario australiana Kym Barrett, quienes integran un colectivo que cocrea el mundo.

- Comprensión aditiva: Los diversos contenidos mediáticos se vinculan hipertextualmente al punto de que cada nueva información puede cambiar el sentido de toda la historia. Como el unicornio de papel en Blade Runner $(1982)^{10}$, los elementos de la representación pueden reestructurar la construcción narrativa cuando son puestos en relación.

La convergencia de tecnologías digitales es una de las claves en la construcción del Universo Matrix, tanto por la innovación en el uso de las imágenes generadas por computadora (CGI) como por las representaciones diegéticas del mundo informático. Al igual que con otras películas, como Tron (Lisberger, 1982) o Hackers (Softley, 1995), se trata de una de las "alegorías populares de lo digital" (Bolter, 2005, p. 17) que representan autorreferencialmente los medios tecnológicos. Quienes tienen roles protagónicos en esta ficción saben programación, tienen competencias y habilidades digitales, "viajan" a través de pulsos telefónicos. Todas estas alusiones que hoy resultan de algún modo anacrónicas se vinculan con la historia del hacking y phreaking ${ }^{11}$ como prácticas mediáticas, que a su vez se replican en las interfaces gráficas de usuario de los videojuegos (el modo hacking en Enter the Matrix, por ejemplo) y el sitio de Internet (www.hackthematrix.com).

También es posible percibir convergencias entre films y videojuegos, vinculadas a la integración tecnológica y las influencias estéticas. Consideramos a las obras audiovisuales del Universo Matrix como obras híbridas entre lo analógico y lo digital. Las imágenes de este Universo producidas entre 1999 y 2003, fueron generadas tanto en película de 35 mm como en archivos digitales. Por tanto, la postproducción de los films así como de los videojuegos combinó ambas tecnologías (analógicas y digitales): procesos físico-químicos como el revelado del soporte fílmico en laboratorio, la copia y corte de negativos, empalmes y bobinados, por mencionar algunos, al tiempo que se generaron imágenes digitales mediante captura directa de fotogramas, diseños $3 \mathrm{D}$ asistidos por computadora y renderizados, entre otras operaciones por computadora. Esta coexistencia de tecnologías es lo que 
Bolter y Grusin denominan remediación, donde "tanto nuevas como viejas formas están involucradas en una lucha por el reconocimiento cultural" (Bolder, 2005, p. 14) ${ }^{12}$. Como producto final de estos procesos previos al proceso de transformación tecnológica que se conoce como roll-out digital ${ }^{13}$ (Fossati, 2019), las copias finales de la primera película fueron distribuidas y proyectadas en salas de cine en soporte fílmico de $35 \mathrm{~mm}$.

En esta pugna entre medios, el cine de fines del siglo XX de algún modo logra invisibilizar las tecnologías digitales en la impresión final del celuloide, mientras que los videojuegos las ponen en evidencia en la interfaz debido a la resolución gráfica de la computadora. Bolter (2005) reconoce que el proceso de remediación afecta mutuamente a los medios implicados, particularmente a los digitales: mientras los videojuegos se apropian de las prácticas de representación del cine, las películas adoptan las técnicas digitales de las imágenes generadas por computadora. Los videojuegos y el cine contemporáneo tienen influencia mutua tanto a nivel narrativo como a nivel estético (Jenkins, 2007). Al analizar el videojuego Enter the Matrix, Diane Carr (2005) retoma la propuesta de Wood (2004), a partir de la cual propone repensar la organización de la estructura narrativa de la primera película como secuencias de juego o niveles, donde el protagonista debe entrenar habilidades y enfrentar desafíos de dificultad creciente. Si bien Jenkins (2008) reconoce que algunos críticos de cine, como Roger Ebert, utilizaron peyorativamente lo que él denomina la "analogía del videojuego", identifica que los usos de un estilo visual similar a los videojuegos "producen una implicación más intensa e inmediata de los espectadores", particularmente con personajes secundarios como Niobe o Ghost para quienes jugaron Enter the Matrix, por ejemplo. Es posible ver en el personaje del Arquitecto, quien desarrolla el mundo virtual de la Matrix, un rol que el mismo Jenkins (2003) había propuesto para quienes diseñan videojuegos.

Lo antedicho sobre los procesos realizados para generar las imágenes del Universo Matrix lleva a la definición de Lev Manovich sobre cine digital, según la cual: "cine digital = material de acción real + pintura + procesamiento de la imagen + composición + animación 2D por ordenador + animación 3D por ordenador" (2006a, p. 376). El montaje, principio estructurante del cine, que permite construir relatos audiovisuales mediante las operaciones de selección, combinación y empalme (Aumont, Bergala, Marie y Vernet, 1996, p. 54) es aplicado indistintamente a la producción cinematográfica y al diseño de videojuegos, donde el uso de escenas filmadas (cinemáticas o cutscenes) ponen en pausa la interactividad y aportan contenidos narrativos. De acuerdo con Bolter (2005, p. 26), tanto en las películas como en los videojuegos se configura una estrategia representacional de la transparencia sostenida en el montaje en continuidad del cine y las imágenes "fotorealistas" de los juegos de computadora.

Las películas del Universo Matrix proponen varias técnicas complejas de representación originales que hibridan lo material y lo digital: el plano Bullet-Time en 1999, que se analiza a continuación; en la segunda entrega, el Burly Brawl (cuando Neo pelea con múltiples clones del agente Smith) y finalmente, el Superpunch (plano detalle del golpe de Neo al Agente Smith en la "batalla final") (Borshukov, 2004, citado en Manovich, 2006b).

El plano Bullet-Time, técnica que le valió el premio Oscar al equipo de VFX (efectos visuales) involucrado en Matrix, es usado en contadas y espectaculares ocasiones, introducido desde la secuencia de apertura de la película al presentar el personaje de Trinity. Ella se 
encuentra delante de una computadora, en una habitación a oscuras. Cuando entra la policía, Trinity entra en combate. Ejecuta un salto y parece que el tiempo que detuviera. La cámara realiza en aparente cámara lenta (slow motion) un travelling circular centrado en su figura negra. La técnica de registro del salto de Trinity (y de Neo esquivando balas, lo que le da el nombre al efecto visual) no se basa en el desplazamiento de la cámara sino en la captura sucesiva de fotografías digitales tomadas por una serie de cámaras alineadas en un semicírculo que rodea al personaje en plena acción, mientras se utiliza un fondo chro$m a-k e y^{14}$ verde que luego será reemplazado por imágenes de rodaje y creadas digitalmente. La producción de este efecto visual depende de un sistema complejo que integra diversas técnicas de generación de imágenes: la cronofotografía de Edward Muybridge, el control de movimiento o motion-control ${ }^{15}$ para la activación de las cámaras digitales, el chro$m a-k e y$ y el diseño 3D del entorno virtual. Las imágenes así generadas luego son editadas, interpoladas y procesadas digitalmente. Esta combinación de técnicas audiovisuales y tecnologías tanto analógicas como digitales fue denominada cinematografía virtual (virtual cinematography) por parte de John Gaeta, quien además de estar a cargo de los VFX de las películas del Universo Matrix, reflexionó abiertamente sobre estos procesos (Manovich, 2006b). El estilo visual de este plano resulta ya familiar para quienes juegan videojuegos desde mediados de los '90s. El desarrollo de la representación digital 3D para juegos de computadora y consolas, particularmente aquellos que construyen su punto de vista en tercera persona, permiten realizar movimientos circulares de cámara centrados en el personaje similares al plano Bullet-Time.

Como innovación del montaje, se basa en la manipulación de la imagen en movimiento de forma tal que es posible pensarlo como una actualización del cine de atracciones, práctica mediática del cine de los primeros tiempos (Stauven, 2006; Røssaak, 2006). Ese efecto "atractivo" para el cine se vuelve disruptivo en el videojuego. En Enter the Matrix, se puede jugar en modalidad "focus", una alternativa limitada (como indica el nivel de carga de una barra lateral a la pantalla) que emula el desplazamiento en cámara lenta con el que Neo esquiva balas en el primer film. Si bien esta modalidad de juego permite realizar movimientos considerados imposibles para la física (caminar por las paredes, esquivar balas, etc.), además de sumar fuerza, la ralentización de los movimientos puede obstruir el desarrollo dinámico del juego. Por su parte, Grusin (2016) denomina "cine de interacciones" (concepto superador del "cine de atracciones") a estas remediaciones del cine digital, post-fotográfico, que ya no requiere un referente material extrafílmico para generar sus imágenes, alejándose de la propuesta ontológica de André Bazin , quien basaba su definición del cine en la semejanza entre la objetividad de la imagen fotográfica y la realidad representada.

La hibridación formal y corporativa en el contexto de las convergencias mediáticas también puede observarse en Animatrix (Jenkins, 2008). Los artistas del animé que participan cuentan con sus propias trayectorias, nuevas referencias que alimentan la narración transmediática: Mahiro Maeda (Neon Genesis Evangelion,1995-1996) dirige The second renaissance parte 1 y 2, Shinichiro Watanabe (Cowboy Bebop, 1998-1999) está a cargo de Kid's Story y A Detective Story, Kōji Morimoto (Akira, 1988) realiza Beyond. En particular, El último vuelo de Osiris fue dirigida por Andrew Jones, que participa en la animación de Final Fantasy: The Spirits Within (2001). Esta película realizada completamente mediante 
CGI, es otra de las referencias multimediales del Universo Matrix, que en este caso remite a la saga de videojuegos lanzada en Japón en 1987 y sostenida hasta la actualidad con diversas producciones mediáticas. La extensión en el tiempo de la franquicia ${ }^{16}$ acompaña los cambios tecnológicos que se fueron dando en las representaciones gráficas de computadora, desde los 8 bits hasta los dispositivos actuales. La "conquista del 3D" en la industria de videojuegos se anticipa a la producción de cine digital ${ }^{17}$.

Las imágenes tanto para este cortometraje del Universo Matrix como para los videojuegos fueron generadas mediante el proceso de mocap (motion capture), técnica de creación de imágenes que ya era aplicada para el desarrollo de videojuegos, desde algunos años antes. Se trata de la creación digital de figuras humanas (cuerpo y rostro), a partir de sensores de movimiento fijados en actores y actrices, que -tal como anuncia su denominación-capturan los movimientos y gestos que realizan. Al igual que el rotoscopiado, que se origina como técnica de animación y es utilizada tanto en cine como en videojuegos, el uso de la captura de movimientos demuestra la permeabilidad entre industrias de producción audiovisual en el contexto de la convergencia tecnológica, y habilita a pensar la arqueología de estos modos de hacer imágenes mediados tecnológicamente.

\section{Arqueologías mediáticas}

En base a lo analizado en la anterior sección, es inevitable entender el Universo Matrix como un conjunto de artefactos culturales generados y mediados por tecnologías. Como se evoca desde la primera microsecuencia (ver supra), las tecnologías mediáticas en el devenir del siglo XX al XXI se relacionan directamente tanto con la construcción narrativa como con los conocimientos que requieren para interpretar el mundo diegético y los desafíos cognitivos que plantea la interpretación de sus imágenes. La arqueología de los medios permite reconocer las materialidades que subyacen a estas tecnologías, investigando cómo lo que puede considerarse como pasado tecnológico se manifiesta en las "nuevas" prácticas mediáticas digitales. En el mismo análisis, es posible reconocer los procesos tecnológicos innovadores en el momento de su producción (1999-2003), que en parte ya se han vuelto obsoletos. Así, este enfoque pone en cuestión la idea de "nuevas" tecnologías en la convergencia digital, recuperando genealógicamente el legado tecnocultural de medios anteriores.

Desandando el camino de la producción de este Universo, el producto final para consumo masivo en DVD ya resulta conflictivo en un paisaje mediático en constante cambio. Tal como recopila William Whittington,

La serie The Matrix ha generado ahora un extenso catálogo DVD. La programación incluye DVDs de The Matrix (un disco único con la película y varias apariciones especiales), The Matrix Revisited (un documental), The Matrix Reloaded (una edición de dos discos con la película y "una explosión de extras que liberarán la mente"), The Matrix Revolutions (que incluye la película y varias apariciones especiales, incluyendo información sobre el juego on-line The 
Matrix) y The Animatrix (un disco de animé y un CD de música). Finalmente, en diciembre de 2004, The Ultimate Matrix Collection fue lanzada como un set en caja con diez discos que incluye material adicional suplementario, arte y links a sitios web $(2007, \text { p. 230 })^{18}$.

A las obras audiovisuales editadas en este formato se agregan los videojuegos Enter the Matrix y The Matrix: Path of Neo, que fueron lanzados tanto para computadora como para PlayStation. La película Matrix alcanzó en su momento el récord de ventas en el entonces nuevo formato DVD: 1,5 millones de copias vendidas en una semana (Graser, 1999). Esta penetración de mercado por parte de Warner Bros. puede explicarse tanto desde la estética visual y la temática de la película como desde la ampliación del horizonte de posibilidades de visualización de un film: detener la imagen en gran calidad, seleccionar escenas, reproducir a mayor velocidad (Tofts, 2007). El propio menú de los DVD brinda opciones de interacción similares a los menúes de selección en los videojuegos, incluso algunas consolas de juego permiten también la reproducción de DVD de películas (otras convergencias, ver Bolder, 2005 y Grusin, 2016). Considerando que la interacción como práctica mediática es una de las características diferenciales de los videojuegos, puede trazarse una "arqueología de la interacción" que, en base al estudio de la cultura material, puede llevar hasta los juguetes ópticos del siglo XIX (Chausovsky y Rossi, 2015) o los libros pop-ups ${ }^{19}$ (Cuadrado, 2018).

Ahora bien, en tanto productos tecnológicos, los DVD deben lidiar con la obsolescencia. Luego de la aparición de los televisores de tecnologías compatibles con computadoras o incluso con conexión remota a otros dispositivos, los reproductores de DVD ya (casi) no se comercializan. La mayoría de las computadoras en venta hoy en día ya no incluyen dispositivos de lectura/escritura de DVD/CD. Aún así, si se conservara un reproductor o dispositivo de lectura, podría accederse a las películas editadas en DVD en una computadora, si ésta tiene instalados los programas informáticos adecuados para leer sus archivos. En el mismo escenario (dispositivo de lectura de DVD conectado a una computadora), no sería tan sencillo acceder, por ejemplo, al videojuego Enter the Matrix, diseñado para sistemas operativos ya obsoletos (Windows 98/2000/XP). Resultaría necesario emular el sistema para instalar el programa de juego. $\mathrm{Si}$, por caso, pudiera disponerse de una consola PlayStation 2 operativa (fue discontinuada en 2013), como ya se mencionó, quizás podría correr tanto los videojuegos como las películas (otro modo de convergencia tecnológica), si y solo si los discos no presentan daño físico como rayas o marcas en su superficie que impidan su reproducción.

Luego del proceso de digitalización de las salas de cine, las copias en $35 \mathrm{~mm}$ de las películas tampoco cuentan con dispositivos de lectura/reproducción en el actual sistema de medios. Es por esta razón que las películas fueron remasterizadas y restauradas digitalmente para editarse en Blu-Ray (4K UHD) y ser proyectadas en salas en formato digital. Esto implicó nuevas operaciones de procesamiento digital de las imágenes, particularmente en el espectro de color. Hoy en día, eludiendo la obsolescencia, las películas pueden verse vía streaming en la plataforma Netflix ${ }^{20}$.

Retomando el complejo sistema de producción del plano Bullet-Time, es posible pensar una genealogía de prácticas mediáticas previas a la realización de Matrix. El propio Gaeta 
(Silberman, 2003) reconoce como referente visual y tecnológico el trabajo de Paul Debevec, particularmente su cortometraje The Campanile Movie (1997) $)^{21}$, en el cual se crea la imagen en movimiento del campanario de Berkeley a partir del modelado y renderizado 3D a partir de una sucesión de fotografías, mientras que el fondo se reconstruye volumétricamente mediante la técnica de la fotogrametría (técnica de representación topográfica del siglo XIX, también utilizada en el diseño 3D de videojuegos). Por tanto, se trata de otro sistema complejo de representación que integra distintas técnicas. Varios autores (Cubitt, 2002; Røssaak, 2006; Rehak, 2007; Plunkett, 2008; Denson y Sudmann, 2013) reconocen otros antecedentes del plano Bullet-Time como la obra de Tim Macmillan ${ }^{22}$, la pieza publicitaria para Smirnoff de Michel Gondry (1996), además de la experiencia de Muybridge. Macmillan realizó en la década del 80 algunas piezas audiovisuales con una técnica que él mismo denominó time slice (rebanar el tiempo), que consistía en registrar una acción desde varios puntos de vista dispuesto en círculo y reconstruir la imagen con movimiento como secuencia. Esta experiencia remite directamente a la técnica precinematográfica de la cronofotografía (Muybridge): una temporalidad analítica, donde la acción se representa en instantes sucesivos. La imagen audiovisual como fragmentos de tiempo.

Así las diversas técnicas aplicadas para realizar el efecto visual del plano Bullet-Time remiten a modos previos de generación de imágenes. La técnica del mocap utilizada para la creación digital de las figuras humanas, que ya se mencionó anteriormente, también se basa en técnicas anteriores. La idea de establecer los sensores de movimiento sobre puntos determinados del rostro o del cuerpo se vincula con los procesos de abstracción necesarios para realizar CGI. Ya en las producciones audiovisuales de la primera etapa de la compañía Pixar se establece la generación de imágenes digitales a partir de la captura de determinados puntos sobre un cuerpo material tridimensional. Así es como se realizó el bebé que aparece en el cortometraje Tin Toy (Lasseter, 1988) o los personajes de Toy Story (Lasseter, 1995). Desde una perspectiva arqueológica, se pueden rastrear estas técnicas digitales en la propia Historia del Arte. La talla y copia de esculturas mediante puntos se basa en el mismo principio de abstracción de la superficie de un cuerpo, que se encuentra en las técnica escultóricas del arte post renacentista o incluso en la Antigüedad. El puntométro es un dispositivo de uso común en el siglo XIX que realiza, a partir del sistema espacial cartesiano, la medición de coordenadas y distancias entre puntos aplicados sobre una escultura para poder reproducirlos por traslación geométrica en el cuerpo de su calco escultórico. Así, esta técnica se establece sobre principios similares de abstracción y representación de imágenes que se aplican en el diseño virtual, tomando un cuerpo de referencia como origen, que es replicado en una copia en base a transformación isométrica.

Por último, es posible establecer relaciones entre las proyecciones en domos de $360^{\circ}$ del formato IMAX y otros espectáculos inmersivos como fueron los panoramas del siglo XIX. Alison Griffiths $(2008 ; 2020)$ investiga esta relación basada en el espectáculo visual y la experiencia corporal. Matrix Reloaded fue el tercer film ${ }^{23}$ remasterizado digitalmente para ser exhibido en este formato (Grusin, 2016). Matrix Revolutions fue la primera película que se estrenó simultáneamente en salas de cine de proyección $35 \mathrm{~mm}$ y salas IMAX.

Con todo, entender estas estrategias de generación, circulación y consumo de las obras del Universo Matrix desde la arqueología de los medios, las inscribe en la historia de la representación visual mediada tecnológicamente. Es posible revisar estas producciones 
multimediales como expresiones relativamente autoconcientes de las apropiaciones y actualizaciones de técnicas y tecnologías involucradas en los procesos estudiados en su relación con dispositivos del pasado. El impacto causado en el público y la industria de los medios trasciende además las propias obras. A más de veinte años de la primera entrega audiovisual de este Universo, el estilo audiovisual logrado y las prácticas mediáticas involucradas en su configuración se replican en la creación de nuevas obras audiovisuales contemporáneas.

\section{Universo híbrido en expansión}

A partir del Universo Matrix se ha podido analizar diversos aspectos de la producción, circulación y consumo de obras audiovisuales. Si bien no este no es el primer universo transmedia, resulta posible reconocer en su estructura narrativa que se trata del primer mundo ficcional concebido transmedialmente. Tampoco es la única propuesta que establece relaciones estéticas entre películas y videojuegos, pero se trata de obras destacadas por el uso de técnicas y tecnológicas, tanto tradicionales como innovadoras, tanto analógicas como digitales.

Luego de analizar los modos de construcción narrativa, algunas de las estrategias manifiestas de convergencia tecnológica y estética que presenta y, finalmente, la dimensión material en la que se sustentan la generación y el consumo de las imágenes de este Universo, podemos entender el Universo Matrix no solo como híbrido sino también como una bisagra entre la producción audiovisual del cine tradicional y la tecnocultura digital, como el Jano bifronte que mira al pasado y al futuro. Las técnicas aplicadas para la representación del espacio, el tiempo y los cuerpos en entornos virtuales, basadas en prácticas mediáticas preexistentes, revelan las continuidades de la historia tecnológica de las imágenes en movimiento.

Walter Benjamin (1989 [1936]) propone en el siglo XX entender la obra de arte en el marco de su reproductibilidad técnica, cuando la posibilidad de copiar fielmente una imagen por medios mecánicos como la fotografía y el cine reconfigura lo que se entiende como Arte y su función social. Su perspectiva busca recuperar la materialidad de las obras, al tiempo que concibe una relación unívoca entre original y copia. En el siglo XXI, la representación del mundo físico desarrollada por las tecnologías digitales desdibuja la noción de original. Ya no se trata entonces de la reproductibilidad técnica sino de una productibilidad sintética que compone una imagen nueva, inexistente en el mundo físico, a partir de múltiples fuentes: figura humana en movimiento, fondos artificiales, espacios creados por computadora. Las posibilidades de creación exploradas en la configuración del Universo Matrix no se agotan en su producción, sino que se replican a otros mundos narrativos y se consolidan como modos de representación, imaginando así universos virtuales en expansión. 


\section{Notas}

1. Anunciada oficialmente por Warner Bros. en agosto del 2019, la producción de esta cuarta entrega se pospuso debido a la pandemia de COVID-19.

Gacetilla de prensa: https://www.warnerbros.com/news/press-releases/lana-wachowskiwrite-and-direct-all-new-film-set-world-matrix-keanu-reeves-and

A pesar de la postergación del rodaje, se ha publicado información sobre el elenco y se anunciaron sucesivas fechas de estreno, siendo la última abril de 2022 (Marshall y Perry, 2021).

2. "Media archaeology sees media cultures as sedimented and layered, a fold of time and materiality where the past might be suddenly discovered anew, and the new technologies grow obsolete increasingly fast" (traducción propia).

3. Es posible considerar este sitio de la Web 1.0 como otra obra más del Universo Matrix. Estuvo en línea entre 1999 y 2009 y ofrecía varios contenidos que remitían a las obras de la franquicia. Internet Archive, a través de su servicio Wayback Machine, conserva más de 5000 capturas del sitio a lo largo de su existencia. También existía la página www. hackthematrix.com, desde el cual se habilitaba la experiencia del "hackeo" de un sistema para acceder a códigos, cadenas de caracteres que permitían acceder a más contenidos en el sitio oficial. Hoy ambas direcciones URL redirigen a https://www.warnerbros.com/ movies/matrix

4. En el webcómic se reproducen diversos textos, visualmente similares al texto plano en computadora, cuyo contenido narrativo está vinculado al momento en el cual se está juzgando un androide mayordomo que asesina a su -hasta ese momento- dueño, en defensa propia (iba a ser desactivado). En el cortometraje, se muestra el momento y los sucesos posteriores al juicio.

5. Disponible para consolas (Xbox, Nintendo GameCube, PlayStation 2) y para PC (Windows 98/2000/Me/XP).

6. MMORPG (massively multiplayer online role-playing game): videojuegos de rol multijugador masivo en línea.

7. The Matrix Online Memory Book. Recuperado de https://archive.org/details/MatrixOn lineMxOOfficialMemorybookStorybookRedPill

8. Ambas hermanas Wachowski han atravesado procesos de transición de género de hombre a mujer. En 2012, Larry Wachowski se declaró mujer transgénero, cambiando su nombre por Lana. Andy lo hizo en el 2016, reconociéndose como Lilly. Su declaración personal puede leerse en Miller (2016).

Respetando su identidad de género autopercibida, nos referimos a ellas en femenino. Esta cuestión puede ser compleja al remitirnos a obras del pasado, anteriores a su transformación, como son las del Universo Matrix (1999-2003). En la secuencia del videojuego que describimos, se presentan en primera persona como Andy y Larry Wachowski. Por esta razón, apelamos a su identidad masculina de ese momento.

9. Propias del animé de ciencia-ficción, como Mazinger Z, los mecha o meka son máquinas o vehículos, generalmente antropomorfos, comandados por pilotos humanos.

10. En el film de ciencia-ficción Blade Runner, dirigido por Ridley Scott, se plantea la duda sobre si el protagonista Rick Deckard (Harrison Ford) es o no un replicante (ser artificial). Gaff (Edward James Olmos), su compañero, con quien investiga replicantes para elimi- 
narles, crea pequeñas figuras de origami a lo largo de la película. Hacia el final del relato, Deckard encuentra en su propia casa un unicornio de origami, que se relaciona directamente con un sueño que tuvo. Esta información visual aporta indicios para argumentar que Deckard es un replicante, ya que de otra forma Gaff no podría conocer su sueño (que sería, entonces, un "recuerdo" artificial, imágenes implantandas en el replicante). Henry Jenkins (2008) se basa en esta información para titular su artículo sobre narración transmedia.

11. "Técnica utilizada para manipular las redes telefónicas" (Prieto, 2000). Contracción de "phone" " "freak" (o "break"), denomina la práctica de "hackear" la red telefónica, anterior a la aparición de las computadoras, que permitía realizar llamadas sin pagar, intervenir líneas teléfonicas, desviar llamadas, entre otras posibilidades. Surge en los años 50 y es popular en la década del 70 (Lapsey, 2005-2014). En España se difunde en los 80 mediante la información compartida en los BBS (Bulletin Board System o tablón de anuncios electrónico) (Molist, 2014).

12. "Both newer and older forms are involved in a struggle for culture recognition." (traducción propia)

13. El roll-out digital es "el momento en que la infraestructura de distribución y proyección digital superó en número a la analógica" (Fossati, 2019, p. XXII).

14. Con la técnica de chroma key se filman las escenas en un set con paredes de fondo color azul o verde (croma), lo que permite luego recortar las figuras en movimiento mediante rotoscopiado, cambiando el fondo de la imagen filmada. Utilizado desde el período clásico-industrial del cine de Hollywood, esta técnica adquiere gran importancia en el marco del desarrollo de las tecnologías digitales, donde los fondos pueden ser creados mediante CGI (López, 2019).

15. Técnica desarrollada para la producción de Star Wars: A New Hope (Lucas, 1979).

16. Al momento, la última entrega del juego es Final Fantasy XV, lanzado en 2016, y se anuncia la salida del Final Fantasy XVI para PlayStation 5.

17. Arsenault, Côté, Larochelle y Lebel (2013) estudian ese pasaje de los gráficos 2D a 3D en la década del 90, planteando que las innovaciones tecnológicas en las técnicas de representación conllevan a nuevos modos de jugar.

18. [The Matrix series has now generated an extensive DVD catalogue. The programming includes DVDs of The Matrix (a single disc with the feature and various special features), The Matrix Revisited (a documentary), The Matrix Reloaded (a two-disc edition with the feature film and "an explosion of mind-freeing extra features"), The Matrix Revolutions (with includes the feature film and various extra features, including information on The Matrix Online game), and The Animatrix (a disc anime and a CD of music). Finally in December 2004, The Ultimate Matrix Collection was release as a ten-disc DVD box set that includes additional supplemental material, artwork, and links to websites]. Traducción de Mariela Cantú para texto de circulación interna para la Cátedra de Análisis y Crítica, Eduardo A. Russo, Facultad de Bellas Artes, UNLP, curso 2012.

19. Los libros pop-ups son libros móviles que despliegan formas tridimensionales al ser abiertos (técnica también utilizada en tarjetas de salutación). Presentan ante quien los lee una experiencia que integra narración e imagen visual animada, e invitan a la interacción táctil con sus figuras (Cuadrado, 2018). 
20. Otra obra obsoleta del Universo Matrix es el sitio web y sus contenidos en línea, tanto porque ya no están disponibles, en un paso efímero por la Internet, como también por basarse en el diseño hipermedial de la primera generación de la Web, en cuyo caso se trata de otro aspecto de la obsolescencia: ésta es percibida, aunque la tecnología (hipervínculos) sigue siendo funcional.

21. Disponible en https://youtu.be/RPhGEiM_6lM . El cortometraje fue presentado en la convención de SIGGRAPH. Más información sobre la realización de esta obra en Debevec (1997-2007).

22. Ver los trabajos tempranos del artista en https://youtu.be/ocLJWCnMhTo

23. Luego de Apollo 13 (1995) y Episodio II: Ataque de los clones (2002).

\section{Lista de referencias bibliográficas}

Alsina, P.; Rodríguez Granell, A. y Hofman, V. Y. (2018). El devenir de la arqueología de los medios: derroteros, saberes y metodologías. Artnodes, (21), 1-12. Recuperado de https:// dialnet.unirioja.es/servlet/articulo?codigo $=7331282$

Aumont, J.; Bergala, A.; Marie, M. y Vernet, M. (1996). El montaje. En Estética del cine (pp. 53-88). Barcelona: Paidós.

Arsenault, D.; Côté, P-M.; Larochelle, A. y Lebel, S. (2013). Graphical technologies, innovation and aesthetics in the video game industry: a case study of the shift from $2 \mathrm{~d}$ to $3 \mathrm{~d}$ graphics in the 1990s. GAME - Games as Art, Media, Entertainment, (2), 79-89. Recuperado de https://www.gamejournal.it/graphical-technologies-innovation-and-aesthetics-in-the -video-game-industry-a-case-study-of-the-shift-from-2d-to-3d-graphics-in-the-1990s/

Bazin, A. (1990). ¿Qué es el cine? Madrid: Rialp.

Benjamin, W. (1989 [1936]). La obra de arte en la época de su reproductibilidad técnica. En Discursos Interrumpidos I: filosofía del arte y de la historia (pp. 17-57). Buenos Aires: Taurus.

Bolter, D. (2005). Transference and Transparency: Digital Technology and the Remediation of Cinema. Intermédialités (6), 13-26. doi: 10.7202/1005503ar

Bolter, D. y Grusin, R. (2011). Inmediatez, hipermediación, remediación. CIC. Cuadernos de Información y Comunicación, (16), 29-57. Recuperado de https://www.redalyc.org/ articulo.oa?id=935/93521629003

Carr, D. (2005). The Rules of The Game, The Burden of Narrative: Enter the Matrix. En Gillis, S. (ed.) The Matrix Trilogy: Cyberpunk Reloaded (pp. 36-47). London: Wallflower.

Chausovsky, A. A. y Rossi, L. S. R. (2015). De los juguetes ópticos a los videojuegos: Discusiones sobre la materialidad de las imágenes. Lúdicamente, 4 (8); 3-18. Recuperado de https://publicaciones.sociales.uba.ar/index.php/ludicamente/article/view/4274

Cuadrado, A. (2018). Arqueología de la interactividad: el libro móvil y pop-up como antecedente de los videojuegos. Artnodes, (21). 119-126. Recuperado de https://www.raco. cat/index.php/Artnodes/article/view/n21-cuadrado/431490

Cubitt, S. (2002). Digital filming and special effects. En Harries, D. (ed.) The New Media Book (pp. 17-30). Londres: British Film Institute. Recuperado de http://hdl.handle. net/11343/34824 
Denson, S. y Sudmann, A. (2013). Digital Seriality: On the Serial Aesthetics and Practice of Digital Games. Eludamos. Journal for Computer Game Culture, 7 (1), 1-32 Recuperado de https://www.eludamos.org/index.php/eludamos/article/view/vol7no1-1

Debevec, P. (1997-2007). The Campanile Movie. Paul Debevec. Recuperado de https://www. pauldebevec.com/Campanile/

Fossati, G. (2019). Del grano al pixel. Cine y archivos en transición. Buenos Aires: AsAECA, Imago Mundi.

Graser, Marc (1999, 1 de octubre). "Matrix" milestone 1.5 mil DVD's sold in record-breaking week. Variety. Recuperado de https://variety.com/1999/film/news/matrix-milestone $-1117756220 /$

Griffiths, A. (2008). Shivers down your spine: cinema, museums and the immersive view. Nueva York: Columbia University Press.

Griffiths, A. (2020). "Escalofríos en la espalda": los panoramas y los orígenes de la recreación cinematográfica. Vivomatografías. Revista de estudios sobre precine y cine silente en Latinoamérica, (6). 462-521. Recuperado de http://www.vivomatografias.com/index. $\mathrm{php} / \mathrm{vmfs} /$ article/view/195

Grusin, R. (2016). DVDs, Video Games, and the Cinema of Interactions. En Denson, S. y Leyda, J. (eds), Post-Cinema: Theorizing 21st-Century Film. Falmer: REFRAME Books. Recuperado de: https://reframe.sussex.ac.uk/post-cinema/1-3-grusin/

Huhtamo, E. y Parikka, J. (ed.) (2011). Media Archaeology: approaches, applications, and implications. Berkeley, Los Angeles, Londres: University of California Press.

Jenkins, H. (2001). Convergence? I Diverge. Technology Review. Recuperado de https://www. technologyreview.com/2001/06/01/235791/convergence-i-diverge/

Jenkins, H. (2003). Game design as narrative architecture. En Wardrip-Fruin, N. y Harrigan, P. (comp.) First Person: New Media as Story, Performance, and Game. Cambridge: MIT Press. Recuperado de http://web.mit.edu/ 21fms/People/henry3/games\&narrative.html

Jenkins, H. (2007). Games, the new lively art. En The Wow Climax: Tracing the emotional impact of popular culture (pp. 19-40). New York: New York University Press.

Jenkins, H. (2008). En busca del unicornio de papel. Matrix y la narración transmediática. Convergence Culture: la cultura de la convergencia de los medios de comunicación (pp. 98-135). Barcelona: Paidós.

Lapsey, P. (2005-2014). FAQ. The history of phone phreaking. Recuperado de http://www. historyofphonephreaking.org/faq.php

López, J. M. (2019). El croma, la verdadera magia del cine. Hipertextual. Recuperado de https://hipertextual.com/2019/03/croma-greenscreen-magia-cine

Manovich, L. (2006a). El lenguaje de los nuevos medios de comunicación: la imagen en la era digital. Buenos Aires: Paidós.

Manovich, L. (2006b). Image future. Animation: an interdisciplinary journal, 1 (1), 25-44. doi: $10.1177 / 1746847706065839$

Marshall, R. y Perry, N. (2021). The Matrix 4: Everything we know about the upcoming Matrix sequel", en Digital Trends. Portland: Designtechnica Corporation. Recuperado de https://www.digitaltrends.com/movies/matrix-4-release-date-news-cast-trailer/

Miller, J. (2016). Second Wachowski Sibling Comes Out as Transgender. Vanity Fair Recuperado de https:/www.vanityfair.com/hollywood/2016/03/andy-wachowski-lilly-transgender 
Molist, M. (2014, 29 de marzo). “Phreakers", los “hackers" del teléfono. El Mundo. Recuperado de https://www.elmundo.es/tecnologia/2014/03/29/53358b87ca474151338b4573.html Parikka, J. (2012). What is Media Archaeology? Cambridge: Polity.

Plunkett J., (2008). From Optical to Digital (and back again). 19: Interdisciplinary Studies in the Long Nineteenth Century, (6). doi: 10.16995/ntn.479

Prieto, J. L. (2000). phreaking. Glosario Terminología Informática. Recuperado de: http:// www.tugurium.com/gti/termino.php? $\mathrm{Tr}=$ phreaking

Proffitt, J. M.; Yune, D. y McAllister, M. P. (2007). Plugging Back into The Matrix: The Intertextual Flow of Corporate Media Commodities. Journal of Communication Inquiry, 31 (3), 239-254. doi: 10.1177/0196859907300955

Rehak, B. (2007). The migration of forms: bullet time as microgenre. Film Criticism, 32 (1), 26-48. Recuperado de: https://works.swarthmore.edu/fac-film-media/47

Røssaak, E. (2006). Figures of Sensation, Between Still and Moving Images. En Strauven, W. (ed.) The cinema of attraction reloaded (pp. 321-336). Amsterdam: Amsterdam University Press.

Salaverría, R. (2003). Convergencia de medios. Revista Latinoamericana de Comunicación Chasqui, (81), 32-39. Recuperado de: https://www.redalyc.org/pdf/160/16008105.pdf

Silberman, Steve (2003, mayo). Matrix 2. Wired. 112-121. Recuperada de: https://archive. org/details/eu_Wired-2003-05_OCR/mode/2up

Scolari, C. A. (2013). Narrativas Transmedia. Cuando todos los medios cuentan. Barcelona: Deusto.

Scolari, C. A. (2009). Alrededor de la(s) convergencia(s): Conversaciones teóricas, divergencias conceptuales y transformaciones en el ecosistema de medios. Signo y Pensamiento, 28 (54), 44-55. Recuperado de https://repositori.upf.edu/bitstream/handle/10230/25461/ Scolari_SiP_Alr.pdf

Strauven, W. (2006). Introduction to an Attractive Concept. En Strauven, W. (ed.) The cinema of attraction reloaded (pp. 11-27) Amsterdam: Amsterdam University Press.

Tofts, D. (2007). Truth at twelve thousand frames per second: The Matrix and time-image cinema. En Hassan, R. y Purser, R. E. (eds.). 24/7: time and temporality in the Network Society (109-121). Stanford: Stanford University Press.

Whittington, W. (2007). What is the Matrix? Sound design in a digital world. En Sound design and science fiction (pp. 223-240). Austin, University of Texas Press.

Wood, A. (2004). The collapse of reality and illusion in The Matrix. En Tasker, Y. (ed.) Action and Adventure Cinema (pp. 119-129). Londres: Routledge.

Abstract: The Matrix Universe is built from works ranging from cinema to video games,
comics and animation. Jenkins (2008) recognizes in this diegetic world, characteristics
that define media convergence, such as co-creation and additive compression. The synergy
of audiovisual production makes the forms of cinema, digital animation and video games
permeable. On the other hand, the representation of and by digital technologies allow 
tracing relationships with both pre-cinema and digital culture, from the perspective of media archeology (Parikka, 2012).

This paper analyzes the construction of this transmedia narrative that Jenkins identifies and characterizes, while recognizing a convergence in the techniques of realization and consumption of digital works.

Keywords: digital cinema - video games - transmedia - convergence - media archeology - Matrix.

Resumo: O Universo Matrix é construído a partir de obras que vão do cinema aos videogames, passando por histórias em quadrinhos e animação. Jenkins (2008) reconhece, neste mundo diegético, características que definem a convergência da mídia, como a co-criação e a compressão aditiva. A sinergia da produção audiovisual torna permeáveis as formas de cinema, animação digital e videogames. Por outro lado, a representação de e por tecnologias digitais permite traçar relações tanto com o pré-cinema quanto com a cultura digital, a partir da perspectiva da arqueologia da mídia (Parikka, 2012).

Este artigo analisa a construção desta narrativa transmídia que Jenkins identifica e caracteriza, ao mesmo tempo em que reconhece uma convergência nas técnicas de fabricação e consumo de obras digitais.

Palavras chave: cinema digital - videogames - convergência - arqueologia da mídia transmídia - Matrix.

[Las traducciones de los abstracts fueron supervisadas por el autor de cada artículo] 